\title{
Technology Orientation, Innovation and Business Performance: A Study of Dubai SMEs
}

\author{
Yahya Al-Ansari, Marwan Altalib, Muna Sardoh \\ Southern Cross Business School, Southern Cross University, \\ Gold Cost Campus, QLD 4225, Australia \\ Emails: y.alansari.10@scu.edu.au,m.mohammed.15@scu.edu.au and m.ahmedsardoh.11@scu.edu.au
}

\begin{abstract}
This study examines how technology orientation interacts with innovation to affect business performance in small and medium-sized enterprises (SMEs) in an emerging market, namely Dubai in the United Arab Emirates. Survey data from 200 Dubai SMEs demonstrated, firstly, that technology orientation influenced innovation and did not have a significant and direct influence on business performance, and secondly, that innovation influenced business performance. Based on these findings, future research avenues are identified and managers of SMEs are advised to consider innovation as a mediating factor for technology orientation to achieve better business performance for their firms.
\end{abstract}

Keywords: technology orientation; innovation; business performance; small and medium-sized enterprises; United Arab Emirates.

\section{Introduction}

The management literature emphasizes the importance of having a high commitment to technology in responding to changing technological conditions. The recommendation is to seek the most efficient and effective technologies to serve existing and new markets with new and better products and services. Research has shown that maximizing innovation is an important strategy for success in the marketplace ${ }^{[1,2,3]}$. An increasing number of studies have explored the impact of strategic orientations (for example technology orientation) on innovation and business performance ${ }^{[4,}$ 5]. Previous studies have focused on Western markets and have yielded mixed results, some positive, some negative and some have found no evidence of an impact $[5,6,7]$.

In emerging markets where the liberalization and privatization of the economy are currently taking place $[8,9,10]$, small and medium-sized enterprises (SMEs) play vital economic roles ${ }^{[11]}$ and have advantages over larger firms in their ability to be innovative ${ }^{[12]}$. SMEs are important engines for innovation and technological advancement ${ }^{[13]}$, although, compared to large firms, they are faced with challenges such as lack of economies of scale, limited resources, smaller market size, and greater vulnerability to market shifts and environmental shocks ${ }^{[14,15]}$. The present study was conducted in an emerging market, namely Dubai in the United Arab Emirates (UAE), which is ranked as the most innovation-driven economy in the Arab world and has been moving from an oil-based economy to a knowledge-based one. Dubai is also changing to a free market economy and is integrating into the world economy ${ }^{[16]}$.

Of the seven states in the UAE, Dubai has been the first to implement major reforms (for example prioritizing economic policy reforms and diversifications and streamlining foreign investment regulations) and it has been the first to establish a strong position in the business world ${ }^{[9,17]}$. In Dubai and elsewhere in the world, SMEs comprise the majority of firms (more than 90\%) in the service and manufacturing sectors ${ }^{[18]}$. To establish in Dubai, SMEs must have a 
minimum of 51\% UAE national-ownership (though full profit repatriation is permitted) or a local agent. Further their staff must have a three-year working visa cycle ${ }^{[17]}$. These legal requirements, combined with weak regulations, an aggressive business and management culture and the internationalization of business activities, have created and a highly competitive environment for SMEs. This is reflected in their innovative potential and long-term technological investment in technology ${ }^{[19,20]}$.

On its Networked Readiness Index, the Global Information Technology Report ranks the UAE $24^{\text {th }}$ among 138 countries ${ }^{[21]}$. The index ranks the countries business environments according to their use of information and communication technology. This ranking shows that there is a general recognition of the importance of technology in in the UAE and Dubai, with the recent development of the Dubai Internet City and Techno Park among other initiatives, creating substantial investment and employment in sectors like information and computer technology ${ }^{[9]}$. This study examines the technology orientation of SMEs and its impact on innovation and business performance in the emerging Dubai market. In the subsequent sections, the research background and hypotheses are presented. The study methods are then introduced including information about the sample, study measures, data analysis, and test results. This is followed by a discussion of the results and their implications as well as the limitations and directions for future research of the study are offered.

\section{Background and Hypothesis Development}

In today's changing business and market environments, firms must develop particular methods and organizational behaviors in order to manage innovation and differentiate themselves from their competitors in order to gain more business opportunities and long-term competitive advantage ${ }^{[22]}$. Examination of the literature reveals that there are three main approaches to innovation theory: the Schumpeterian view in which the entrepreneur is seen as causing a continual disturbance to the equilibrium of the market and makes a major contribution to innovation; the Marshallian view in which the innovation system is seen in terms of the original concept of industrial districts; and the technology-push/market-pull view in which the rate and direction of innovation within a firm can be determined by technology-push based on scientific and technological changes and/or by market-pull based on unmet customer and market needs ${ }^{[23]}$. This study is concerned with the third approach. According to this school, a firm needs to find 'technology-push' to efficiently and effectively provide superior customervalue and 'market-pull' with new and better products and services to reduce costs and maximize profits ${ }^{[24]}$. In the marketplace, the competitive firm seeks to transform technological and market conditions through the input of resources to generate useful (high quality), affordable (low cost) and innovative products and services. In this context, innovation is related to the ability of the firm to seek new and better ways of generating, acquiring, and implementing tasks (processes, products, services, management and administrative systems, organizational structures and marketing methods) in the organization [25].

Innovation has interactive demand-side (customers) and supply-side (research outcomes) elements ${ }^{[26,27]}$. It is important for a firm to evaluate their competitive strategies and incorporate innovation at the organizational level and in their activities in order to achieve better business performance ${ }^{[28]}$. A firm can use different technologies to internally create a new and better process, product or service for the market that it is centered on the innovation outcomes ${ }^{[29]}$. This study adopts a core-competence approach. The examination of the role of internal resources and capabilities can provide a better understanding of innovative potential and continuous innovative activities within a firm. This understanding can help a firm to achieve better business performance ${ }^{[23,30]}$. From a core-competence view, it is interesting to analyze the links between the technology orientation of SMEs and their innovation and business performance and to explore whether such links exist in an emerging market context.

\subsection{The core competence-based view}

The core competence-based view of strategic management considers a firm's core competencies as the source of its collective learning and sustainable competitive advantage ${ }^{[31]}$. Core competencies are the integrated collection of capabilities (organizational routines and problem-solving skills) that distinguish the firm in the marketplace. Core competencies are difficult for other firms to imitate ${ }^{[22]}$. This view is linked to the market dynamics concept of 'dynamic capabilities.' 
According to this view, organizational structures, procedures, skills and decision-making rules determine the manager's ability to build, integrate and reconfigure the firm's internal and external capabilities and competences. Building these core competencies enables the firm to obtain strategic fit with its changing environments in order to create opportunities and capture values for long-term profitability ${ }^{[32]}$. Dynamic capabilities differ with changing market environment creating strategic flexibility and sustaining competitive advantage through specific objectives and creative behaviors, which are later considered to be patternoriented $^{[33]}$.

The advantages of the firm are in 'responding quickly with innovations that meet specific market needs, while simultaneously exploring basic research areas for potentially major innovations that more significantly alter the market landscape' ${ }^{[1, p .16]}$. This is why the firm's innovation efforts should be focused on nurturing and enhancing these capabilities and competences in order to achieve better business performance. The rate and direction of innovation within the firm can be driven by 'technology-push' based on scientific and technological changes and/or by 'market-pull' based on unmet market needs ${ }^{[23,34]}$. Firms are experiencing a shift from 'technology-push' to 'market-pull' due to increasing customer sophistication and the complexity of customers' needs ${ }^{[35]}$. Von Hippel [36] argues that firms creating products and services in response to 'market-pull' rather than 'technology-push' are more successful in meeting customers' needs. Firms need to have new product and service development structures that are balanced with a greater integration of internal technologies and external needs ${ }^{[35]}$. So, successful innovation requires the firm to connect technical and market opportunities for better business performance ${ }^{[34]}$. However, this study is concerned with the "technology-push" of the firm and so it explores the links between technology orientation, innovation and business performance in the context of SMEs in Dubai because of the recent major investments by the Government of Dubai in the information and communication technology sectors ${ }^{[9]}$.

\subsection{Technology orientation and innovation}

The technical proficiency of the firm is an important factor in developing new processes, products and services ${ }^{[37,38]}$. The firm's internal technology policy reflects its innovative attitude and commitment to innovation $[39,40]$. Attitudes to technology and innovation can determine the firm's achievement of competitive advantage ${ }^{[41]}$. Firms that proactively acquire new and advanced technologies might be more innovative owing to their emphasis on applying these technologies to developing new processes, products and services to meet customer needs ${ }^{[42]}$. The level of technology orientation of a firm has a significant influence on its ability to innovate and is viewed as being a source of competitive advantage ${ }^{[43]}$, which can lead to better business performance ${ }^{[44]}$. Salavou et al. [12] argues that SMEs with limited resources may seek innovation along the value chain. Such innovations require less investment in technological adoption and/or development. However, technological adoption and/or development in Dubai vary for different SMEs due to a dynamic and a highly competitive marketplace, rapid technological change and a short visa cycle. These factors may influence their long-term investment in technological resources and capabilities and in turn their innovation outcomes $[9,20,45]$. So, the following hypothesis is proposed:

H1: Technology orientation will have a significant positive effect on a firm's innovation.

\subsection{Technology orientation and business performance}

Technologically-oriented firms devote their resources to acquiring new and advanced technologies and developing new processes, products and services, although, the rate of technological changes within an industry might affect their technological adoption and/or development ${ }^{[5]}$. Previous studies have found positive relationships between technology orientation and business performance ${ }^{[2]}$. The importance of technology orientation to innovation has been long recognized ${ }^{[43]}$, but the relationship between technology orientation and business performance has been given only minimal attention in the literature ${ }^{[4]}$. Firms that have a high technology orientation gain better business performance when technology changes rapidly because they are able to introduce new processes, products and services to satisfy customer needs ${ }^{[45]}$. Technologically-oriented firms that combine customer-value innovation with technological innovation have an increased chance of enjoying sustainable profit and performance ${ }^{[2]}$. 
However, given the technological advances in the dynamic Dubai market, SMEs need to experiment with new technologies in order to survive ${ }^{[5,46]}$. So, the following hypothesis is proposed:

H2: Technology orientation will have a significant positive effect on a firm's business performance.

\subsection{Innovation and business performance}

Innovation is an important determinant of business performance in a changing competitive environment ${ }^{[47]}$. Business performance is related to the ability of the firm to gain profit and growth in order to achieve its general strategic objectives ${ }^{[25]}$. Business performance is the result of the interplay between actions taken in relation to competitive forces that allow the firm to adapt to the external environment, thereby integrating the efficiency and effectiveness ${ }^{[48]}$. Keizer et al. ${ }^{[49]}$ emphasize that the firm's innovation performance depends on the opportunities provided by their external environment. SMEs in Dubai can use innovation as a tool to achieve better business performance ${ }^{[6]}$, having in mind that important innovations are those that contribute to business performance ${ }^{[25]}$. Some studies have found a significant relationship between innovation and sales growth and profitability ${ }^{[50]}$ while others have found a non-significant relationship between innovation and return on investment ${ }^{[6]}$, but the link between innovation and business performance needs to be tested in a different market context ${ }^{[51]}$. So, the following hypothesis is proposed:

H3: Innovation will have a significant positive effect on a firm's business performance.

\section{Methods}

\subsection{Sample design}

To test the hypotheses, this study utilizes a sample of SMEs in the following industries: information and communication technology, healthcare services, entertainment and media, construction and architecture, manufacturing and industrial engineering, retail and consumer goods and trading and repairing services. A range of industries was included so as to generalize beyond particular industries, to the population of SMEs ${ }^{[52]}$. This study adopts a definition of SMEs based on the number of employees as small (1-9 employees), medium (10-199 employees), and large (more than 200 employees) ${ }^{[18,53]}$. A sample of 600 SMEs was identified using a stratified sampling technique based on firm size using the Dubai Chamber of Commerce and Industry database ${ }^{[54]}$.

\subsection{Variable measurement}

The items used to measure the three constructs are based on an extensive review of related literatures. The following items of the independent, intervening and dependent constructs were measured using a sevenpoint Likert scale. The items for technology orientation, independent latent variable, were measured with end points of "1-strongly disagree" and "7-strongly agree." The items for innovation, intervening latent variable, were measured with end points of "1-much below" and "7-much above." The items for business performance, dependent latent variable, were measured with end points of "1-much worse" to "7-much better."

Technology orientation was measured on a five-item scale in responses to survey questions relating to technological policy, position, and adoption, adapted from Allocca and Kessler ${ }^{[11]}$, Salavou et al. ${ }^{[12]}$ and Aragon-Sanchez and Sanchez-Marin [55] studies. Innovation within a three-year time period was measured using a ten-item scale in responses to survey questions about practices adopted from Blumentritt and Danis ${ }^{[33]}$, Aragon-Sanchez and Sanchez-Marin ${ }^{[55]}$ and Calantone et al. ${ }^{[56]}$ studies. Business performance within a three-year time period was measured using an eleven-item scale in responses to survey questions about performance adopted from Aragon-Sanchez and Sanchez-Marin ${ }^{[55]}$, Klomp and van Leeuwen ${ }^{[57]}$ and Linder ${ }^{[58]}$ studies. It should be noted that due to confidentiality concerns, a self-reporting financial and non-financial measures were used ${ }^{[59]}$.

Before data collection, the content validity of the survey was established by grounding it in the existing literature. To ensure it was suitable for Dubai SMEs, the survey was pre-tested with owners/managers of SMEs, academic researchers, and industry and market experts $(n=30)$. They were asked to review the survey for structure, readability, ambiguity and completeness ${ }^{[60]}$. The final version was sent to another sample of SMEs $(n=24)$ to be pilot tested. To assess the reliability and validity (internal consistency) among constructs and items in the scales, the coefficient alpha and average 
item-total correlations and inter-item correlations among constructs and items in the scales were calculated. The coefficient alphas for all constructs were above the cutoff value of 0.60 and the internal consistencies (item-to-total and inter-item correlations) for all items were above the minimum levels of 0.50 and $0.30^{[61]}$.

\subsection{Data collection}

The data used to test the hypotheses were drawn from a structured survey of target respondents from SMEs in various industries in Dubai in the UAE. These individuals had senior levels of responsibility and their values and philosophies were likely to influence the strategic choices and decisions of their firms ${ }^{[62]}$. Three weeks after the first delivery of surveys and introductory letters, reminder letters were sent out to non-respondents ${ }^{[63]}$. Of the 600 surveys sent (see Table 1), 208 surveys were returned, resulting in a response rate of $34.67 \%$ (208/200). A total of eight surveys were discarded due to incomplete information, resulting in an effective response rate of $33.33 \%(200 / 600)$.

Statistical comparison of those responding before $(n=150)$ and after $(n=50)$ the three-week period found no significant differences in the mean values of study measures, ruling out non-response bias ${ }^{[63]}$. As this study collected data from a single respondent in each responding firm, a test for common method bias was also conducted by using the Harman's single factor test to calculate the un-rotated factor analysis with an eigenvalue-greater-than-one criterion, which revealed that three distinct factors accounted for $64.78 \%$ of the variance with the first factor capturing only $44.41 \%$. A single factor did not emerge from the factor analysis and the first factor did not account for most of the common variance. This means that common method bias did not appear to be a problem ${ }^{[64]}$.

\section{Analyses and Results}

The Partial Least Squares (PLS) modeling method was selected to test the measurement and structural models using component-based approach ${ }^{[65]}$. The PLS method was appropriate because it focuses on prediction of data, is suited to exploratory study and has a different requirement for data distribution characteristics (for example normality, skew and kurtosis) that avoids many restrictive assumptions such as the need for multivariate normality ${ }^{[66]}$. Before testing the proposed hypotheses, a series of tests was performed to verify and establish the uni-dimensionality of the measures using two-stage approaches that are measurement and structural model estimations ${ }^{[67]}$. It should be further noted that this study applies a reflective construct model in which items are affected by their latent variables ${ }^{[68]}$.

\subsection{Measurement model}

The measurement model consists of fifteen measured items and three latent variables. A centroid weighting scheme (300 maximum iterations) and an abort criterion for the iterative estimation process were selected as a change of the estimated values of just $0.1-5 \%$ between two iterations ${ }^{[66]}$.

To establish the reliability and validity of the latent variables and their items in the outer model, first, the individual item reliability, Cronbach's alpha and composite reliability were above the recommended

Table 1. Sample composition.

\begin{tabular}{|c|c|c|c|c|}
\hline \multirow[b]{2}{*}{ Industry } & \multicolumn{3}{|c|}{ Firm Size } & \multirow[b]{2}{*}{ Total $^{\text {bc }}$} \\
\hline & 1-9 Employees & 10-99 Employees & 100-199 Employees & \\
\hline Information and Communication Technology & 18 & 38 & 7 & $63(31.5)$ \\
\hline Healthcare Services & 9 & 17 & 1 & $27(13.5)$ \\
\hline Entertainment and Media & 19 & 4 & 4 & $27(13.5)$ \\
\hline Manufacturing and Industrial Engineering & 7 & 13 & 6 & $26(13)$ \\
\hline Construction and Architecture & 5 & 6 & 4 & $15(7.5)$ \\
\hline Retail and Repairing Services & 5 & 8 & 1 & $14(7)$ \\
\hline Other Services $^{\mathrm{a}}$ & 10 & 15 & 3 & $28(14)$ \\
\hline Total & 73 & 101 & 26 & $200(100)$ \\
\hline
\end{tabular}

${ }^{a}$ Other services include financial intermediation and insurance, education, training, and consultancy, tourism and hospitality, and real estate and renting services.

${ }^{\mathrm{b}}$ Eight surveys are incomplete. Three are from information and communication technology and five are from other services.

${ }^{\mathrm{c}}$ Percentage figures are given in parentheses. 
0.60/0.707 criterion (see Table 2), which indicates that items were performing well in capturing latent variables ${ }^{[69]}$. Second, the Average Variance Extracted (AVE) was above the recommended 0.50 threshold (see Table 2), which indicates that for every latent variable more than $50 \%$ of the variance was explained ${ }^{[67]}$. Third, the convergent and discriminant validities were above the recommended 0.707 minimum loadings value (see Table 2 and Table 3), which indicates that all latent variables were strongly correlated with their own items, with the exception of the business performance latent variable that was subdivided for simplicity, and at least $50 \%$ of the variance was shared with the latent variable [70].

The discriminant validity was further evaluated at two levels (see Table 2). At the item level, the factor analysis of each item's cross-loadings revealed that the items loaded onto their respective latent variables to the highest degree and that no item loaded higher onto other latent variables than on its respective latent variable, which assumes item discriminant validity ${ }^{[71]}$. At the latent variable level, the comparison of each latent variable squared root $\mathrm{AVE}$ and its correlation suggested that there is satisfactory discriminant validity since the squared root AVE for each latent variable exceeded the respective latent variable correlations with any other latent variables in the outer model and there are low correlations between latent variables ${ }^{[69]}$.

The results are reasonable for newly developed scales to be tested in different context like the Dubai situation ${ }^{[70]}$. With these results, it was concluded that reliability, AVE and convergent and discriminant

Table 2. Outer-loadings, reliability, AVE, cross-loadings and correlations.

\begin{tabular}{lcccccc}
\hline \multicolumn{1}{c}{ Latent Variables } & $\begin{array}{c}\text { Outer- } \\
\text { Loadings* }\end{array}$ & Cronbach's $\alpha$ & $\begin{array}{c}\text { Composite } \\
\text { Reliability }\end{array}$ & AVE & $\begin{array}{c}\text { Cross- } \\
\text { Loadings* }\end{array}$ & $\begin{array}{c}\text { Correlations } \\
\text { Matrix** }\end{array}$ \\
\hline Technology orientation & $0.805-0.844$ & 0.886 & 0.916 & 0.687 & $0.805-0.844$ & $0.828(0.370-0.636)$ \\
Innovation & $0.721-0.796$ & 0.923 & 0.934 & 0.586 & $0.721-0.796$ & $0.766(0.523-0.639)$ \\
Business performance & $0.702-0.889$ & 0.867 & 0.905 & 0.656 & $0.702-0.889$ & $0.810(0.370-0.523)$ \\
\hline
\end{tabular}

* Outer-loadings and cross-loadings include the lowest and highest loadings.

** Correlation matrix column includes squared root AVE and correlations in bracket.

Table 3. Construct measurement items.

\begin{tabular}{lr}
\hline Latent Variables & Loadings $^{\mathrm{a}}$ \\
\hline Technology Orientation & $0.805-0.844$ \\
Item1: Our firm's policy is to adopt up-to-date technologies & 0.805 \\
Item2: Our firm purchases and uses technologies to position itself ahead of competitors & 0.844 \\
Item3: Our firm is often to be first to try out new methods and technologies & 0.838 \\
Item4: Our firm frequently improves internal processes such as speed, reliability, and information management & 0.812 \\
Item5: Our firm allocates resources for investments in latest technologies and future forecasted technological changes & 0.842 \\
Innovation & $0.721-0.796$ \\
Item1: Our firm frequently tries out new ideas & 0.721 \\
Item2: Our firm introduces number of new products, services, processes, or organization/management systems & 0.734 \\
Item3: Our firm is first to market with new products or services & 0.796 \\
Item4: Our management seeks out new ways to do things & 0.771 \\
Item5: Our firm is creative in its methods of operation & 0.794 \\
Item6: Our firm uses up-to-date technologies & 0.764 \\
Item7: Our firm develops new market segments & 0.785 \\
Item8: Our firm uses new marketing methods & 0.783 \\
Item9: Our firm develops new ways of establishing relationships with customers & 0.759 \\
Item10: Our firm spends resources on research and development for new products, services, or processes & 0.746 \\
Business Performance & $0.702-0.889$ \\
Item1: Our firm's customer satisfaction & 0.701 \\
Item2: Our firm's sales growth & 0.867 \\
Item3: Our firm's profit growth & 0.889 \\
Item4: Our firm's return on investment & 0.792 \\
Item5: Our firm's market share & 0.788 \\
\hline
\end{tabular}

${ }^{\mathrm{a}}$ Outer-loadings and cross-loadings are included.

Published by Atlantis Press

Copyright: the authors 
validities made it acceptable to proceed with the analysis.

\subsection{Structural model}

The structural model consists of three latent variables. To estimate the parameters in the inner model, a bootstrapping procedure with 200 and 500 re-samples consisting of the same number of cases as the original sample (that is, 200) was applied to assess the quality of the estimated structural model parameters [67, 70]. Potential sign changes were treated by means of the option of individual sign changes. The goodness of the conceptual model was established by the strength of each structural path and the combined productiveness of its independent latent variables ${ }^{[67]}$. Blindfolding (communality and redundancy) on the latent variable innovation with 7 and 21 omission distances was applied.

First, the variance explained by the inner model in terms of the Squared Multiple Correlations $\left(\mathrm{R}^{2}\right)$ was examined (see Table 4). The $\mathrm{R}^{2}$ value is between 1 and 0 and higher than the cut-offs of $0.67,0.33$ or 0.19 levels for substantial, moderate or weak correlations in that order ${ }^{[67,69]}$. The $\mathrm{R}^{2}$ values for innovation and business performance were 0.409 and 0.276 . The $\mathrm{R}^{2}$ was satisfactory and indicated that $40.9 \%$ of the variation in the degree of innovation was explained and significantly influenced by technology orientation, while $27.6 \%$ business performance was accounted for by innovation. With these outcomes, it was concluded that $\mathrm{R}^{2}$ was of moderate strength.
Second, the goodness-of-fit (GoF) was calculated by the square root of the geometric mean of the average of the $\mathrm{R}^{2}(0.342)$ multiplied by the cross-validated communality $(0.621)^{[72]}$. The GoF value higher than $0.36,0.25$ or 0.10 levels that are considered to indicate large, medium and small model fits in that order ${ }^{[73]}$. The GoF is 0.461 and that is considered to be a large model fit. To further assess the predictive relevance and stability of the inner model, the Stone-Geisser test $\left(Q^{2}\right)$ produced values consistently higher than zero (between 0.589 and 0.656 ) indicating that the prerequisites of predictive relevance for the structural model were fulfilled ${ }^{[69]}$.

Third, the path coefficients and $t$-values $(p<0.05)$ were calculated (see Table 4). The hypotheses were tested by examining the magnitude of the standardized parameter estimates between latent variables together with the corresponding $t$-values $(>1.96, p<0.05)$. The results support $\mathrm{H} 1$ and $\mathrm{H} 3$. Technology orientation has a significant positive correlation with innovation $(\mathrm{H} 1$ : $0.639 / 15.550)$, and it has a non-significant correlation with business performance (H2: 0.060/0.880). Innovation has a significant positive correlation with business performance (H3: 0.485/5.718). The path coefficients estimates and $t$-ratios were recalculated using the bootstrap routine of 200 and 500 re-samples for the latent variable innovation (see Table 5). The path coefficients were very stable with respect to the original sample estimates and three paths were revealed as significant, yielding identical results to those reported for the original sample above.

Table 4. Structural model $\mathrm{R}^{2}$, path coefficients and $t$-values.

\begin{tabular}{lccc}
\hline \multicolumn{1}{c}{ Latent Variables } & $\mathrm{R}^{2}$ & Path Coefficients & $t$-Values* \\
\hline H1: Technology orientation $\rightarrow$ Innovation & 0.409 & 0.639 & 15.550 \\
H2: Technology orientation $\rightarrow$ Business performance & 0.276 & 0.060 & 0.880 \\
H3: Innovation $\rightarrow$ Business performance & 0.276 & 0.485 & 5.718 \\
\hline
\end{tabular}

* The $t$-values were significant at $p<0.05,0.01$ and 0.001 except technology orientation and business performance.

Table 5. Path coefficients and total effects of 200 and 500 bootstrapping procedures measures.

\begin{tabular}{|c|c|c|c|c|}
\hline Latent Variables & Original Sample & Mean of Resample* & $t$-Ratios** & Supported \\
\hline \multicolumn{5}{|l|}{ Total Effects on Innovation $\left(\mathrm{R}^{2}=0.409\right)$} \\
\hline H1: Technology orientation (+ Sign) & 0.639 & $0.643(0.642)$ & $15.550(13.800)$ & Yes \\
\hline \multicolumn{5}{|c|}{ Total Effects on Business Performance $\left(\mathrm{R}^{2}=0.276\right)$} \\
\hline $\mathrm{H} 2$ : Technology orientation (+ Sign) & 0.060 & $0.086(0.090)$ & $0.880(0.914)$ & No \\
\hline H3: Innovation (+ Sign) & 0.485 & $0.494(0.485)$ & $5.718(5.426)$ & Yes \\
\hline
\end{tabular}

* The 500 re-sample values are in bracket.

** The $t$-ratios were significant at $b<0.05 .0 .01$ and 0.001 excent technologv orientation and business performance. 
The relative path coefficient strengths at the structural level were further evaluated by the size effects (see Table 5). This was done using Cohen's [74] recommended gauges of $>0.02$ for weak, $>0.15$ for medium and $>0.35$ for strong effects. Technology orientation has a strong effect on innovation and innovation has a strong effect on business performance. Further, technology orientation has a weak effect on business performance.

\section{Discussion}

This study examines the impact of the technology orientation on innovation and the business performance of SMEs in the emerging Dubai market in the UAE. The findings, just as has been observed for Western markets, support two of the three hypotheses and reveal that technology orientation has a significant positive correlation with innovation and innovation has a significant positive effect on business performance in emerging markets. So, even in an emerging market like Dubai, technology orientation influences the degree of emphasis placed on innovation and this in turn affects business performance. Based on the findings, a number of outcomes can be offered regarding the role of technology orientation, innovation and business performance within SMEs.

First, SMEs have a positive orientation towards technology that has a significant effect on their innovation. This finding is consistent with previous studies ${ }^{[43]}$. The results show that SMEs in Dubai are likely to use technology to support their innovative activities and that they have realized that their technology policies and the adoption of new technology play important roles in improving their internal processes and methods and this motivates them to allocate resources for investments in the latest technologies to support innovation. So, the use of technology by SMEs might be considered to be innovative behavior ${ }^{[75]}$.

Second, the finding of a weak effect of technology orientation on business performance is similar to the findings of previous studies ${ }^{[5]}$. The link between technology orientation and business performance might not be linear and is mediated through innovation. This finding is consistent with a previous study ${ }^{[45]}$. This may be explained by the slow pace of technological changes in the Dubai market and the tendency of local SMEs to develop incremental technologies or adopt advanced technologies through licensing or joint-ventures from foreign firms entering the local market.

Third, innovation has a strong effect on business performance within SMEs in the context of Dubai. This finding is consistent with previous studies ${ }^{[25]}$. Innovation permits SMEs to achieve competitive advantage and this contributes to their business performance ${ }^{[76]}$. Innovation appears to be a wise choice for Dubai SMEs which will enable them to gain better business performance despite many foreign firms entering the market with advanced innovations. This reflects an understanding of customer needs, competitor actions and technological developments that can lead to new processes, products, services and market spaces ${ }^{[77]}$. So, the positive link between innovation and business performance may help SMEs in Dubai develop better long-term strategies and competitive advantages and improve their innovativeness regardless of the speed of change in the market as a whole.

\subsection{Managerial implications}

This study makes a number of guidelines and implications for SMEs in Dubai. SMEs in Dubai can either develop incremental technologies or adopt advanced technologies through licensing or jointventures with foreign firms who entered the local market with new or advanced technologies. They also need to customize technologies to suit the local market demands. This could encourage policymakers in Dubai to invest in technology centers and institutions to facilitate and finance technologies across different SMEs industries. A technology fund as well for SMEs to tap into is a step forward to strengthen the knowledge capital and innovation levels of the Dubai market. Further, SMEs in Dubai need to be aware of technological changes within their industry in order to be actively involved in new process, product and service developments to be able to innovate and survive in a changing market environment. SMEs that placed a much emphasis on technological resources and capability to survive in the local market demonstrated a non-significant relationship to their business performance. However, innovation that brought changes to the local market resulted in more economic benefits for the firms. So, managers of SMEs looking to enhance business performance are advised to consider innovation as a mediating factor for technology orientation to achieve better business performance for their firms. 


\subsection{Limitations and directions for future research}

This study emphasizes the importance of technology orientation and links it to innovation and business performance but it does not consider other strategic orientations (such as market orientation). Nor does it address the issue of how technology orientation and innovation are carried out. This is a topic for future research. Further, the effect of technology orientation components at different stages of innovation needs to be examined. Another limitation is the unit of analysis, the perceptions of top management personnel. There is a need to understand the role of individuals in the strategic actions of the firm and how they affect innovation performance. By using multiple respondents (from different function units or management levels) in each firm, a clearer picture could be developed from inside the firm. This study is also limited by its crosssectional design; a longitudinal study could better assess the relationships over time. The absence of the significant relationship between technology orientation and business performance is an interesting finding and provide an opportunity for further research. Although the study was conducted in Dubai, many countries in the Middle East, Africa, Asia, Latin America and the Caribbean encounter similar situations. Further research is necessary to examine this.

\section{Conclusions}

This study examines the role of technology orientation in driving SMEs in Dubai to innovate. It lends support to previous studies undertaken in Western markets and provides useful insights into innovation and the business performance of SMEs in emerging markets. The results reveal that technology orientation influences behaviors and tendencies of SMEs regarding innovation in the Dubai marketplace and that the link between technology orientation and business performance is mediated by innovation.

\section{References}

1. S.R. Chidamber and H.B. Kon, A research retrospective of innovation inception and success: The technologypush demand-pull question, International Journal of Technology Management, 9(1) (1994) 1-27.

2. Gatignon and J-M. Xuereb, Strategic orientation of the firm and new product performance, Journal of Marketing Research, 34(1) (1997) 77-90.

3. A. Brem and K-I. Voigt, Integration of market pull and technology push in the corporate front end and innovation management-insights from the German software industry, Technovation, 29(5) (2009) 351-367.

4. I. Jeong, J.H. Pae and D. Zhou, Antecedents and consequences of the strategic orientations in new product development: The case of Chinese manufacturers, Industrial Marketing Management, 35 (2006) 348-358.

5. G.Y. Gao, K.Z. Zhou and C.K. Yim, On what should firms focus in transitional economies? A study of the contingent value of strategic orientations in China, International Journal of Research in Marketing, 24 (2007) 3-15.

6. H. Forsman and S. Temel, Innovation and business performance in small enterprises. An enterprise-level analysis, International Journal of Innovation Management, 15 (2011) 641-665.

7. J. Spanjol, S. Muhlmeier and T. Tomczak, Strategic orientation and product innovation: Exploring a decompositional approach, Journal of Product Innovation Management, 29 (2012) 967-985.

8. L.K. Mytelka, Local systems of innovation in a globalised world economy, Industry and Innovation, 7 (2000) 15-32.

9. J. Grant, F.S. Golawala and D.S. McKechnie, The United Arab Emirates: The twenty-first century beckons, Thunderbird International Business Review, 49 (2007) 507-533.

10. B. Rettab, A.B. Brik and K. Mellahi, A study of management perceptions of the impact of corporate social responsibility on organisational performance in emerging economies: The case of Dubai, Journal of Business Ethics, 89 (2009) 371-3900.

11. M.A. Allocca and E.H. Kessler, Innovation speed in small and medium-sized enterprises, Creativity \& Innovation Management, 15(3) (2006) 279-295.

12. H. Salavou, G. Baltas and S. Lioukas, Organisational innovation in SMEs: The important of strategic orientation and competitive structure, European Journal of Marketing, 38(9-10) (2004) 1091-1112.

13. A. Mulhern, The SMEs sector in Europe: A broad perspective, Journal of Small Business Management, 33(3) (1995) 83-89.

14. B. Tether, Small and large firms: Sources of unequal innovations? Research Policy, 27 (1998) 725-745.

15. R. Cagliano, K. Blackmon and C. Voss, Small firms under the microscope: International differences in production/operation management practices and performance, Integrated Manufacturing Systems, 12(7) (2000) 469-482.

16. J. Knight, Education hubs: A fad, a brand, an innovation? Journal of Studies in International Education, 15(3) (2011) 221-240.

17. BMI, The UAE Business Forecast Report, (Business Monitor International LTD, UAE, 2007).

18. DCCI, Dubai Chamber of Commerce and Industry database, (The Information Centre, Dubai, 2010).

19. A.A. Elewa, New UAE Commercial Companies Law Soon, (Gulf News, January 26 2007). 
20. A.B. Brik, B. Rettab and K. Mellahi, Market orientation, corporate social responsibility, and business performance, Journal of Business Ethics, 99 (2011) 307-324.

21. GITR, The Global Information Technology Report, (INSEAD/ World Economic Forum, France, 2010-2011).

22. D.J. Teece, Technological innovation and the theory of the firm: The role of enterprise-level knowledge, complementarities, and dynamic capabilities in Handbooks in Economics, eds. B.H. Hall and N. Rosenberg (Elsevier B.V, Amsterdam, 2010), pp. 679730 .

23. A-M. Hjalager, A review of innovation research in tourism, Tourism Management, 31 (2010) 1-12.

24. S.F. Slater, Developing a customer value-based theory of the firm, Journal of Academy of Marketing Science, 25(2) (1997) 162-167.

25. G.T.M. Hult, R.F. Hurley and G.A. Knight, Innovativeness: Its antecedents and impact on business performance, Industrial Marketing Management, 33(5) (2004) 429-438.

26. D.C. Mowery and N. Rosenberg, The influence of market demand upon innovation: A critical review of some recent empirical studies, Research Policy, 8 (1979) 102153.

27. K. Mole and L. Worrall, Innovation, business performance, and regional competitiveness in the West Midlands: Evidence from the West Midlands business survey, European Business Review, 13(6) (2001) 353364.

28. R. Vossen, Relative strengths and weaknesses of small firms in innovation, International Small Business Journal, 16(3) (1998) 88-94.

29. S. Myers and D.G. Marquis, Successful Industrial Innovation: A Study of Factors underlying Innovation in Selected Firms, (National Science Foundation, Washington, 1969).

30. J.A. Martinez-Roman and J. Gamero and J.A. Tamayo, Analysis of innovation in SMEs using an innovative capability-based non-linear model: A study in the province of Seville (Spain), Technovation, 31(9) (2011) 459-475.

31. A. Heene and R. Sanchez, Competence-Based Strategic Management, (John Wiley \& Sons Inc., New York, 1997).

32. K.M. Eisenhardt and J.A. Martin, Dynamic capabilities: What are they? Strategic Management Journal, 21(1011) (2000) 1105-1121.

33. T. Blumentritt and W.M. Danis, Business strategy types and innovative practices, Journal of Management Issues, 18(2) (2006) 274-291.

34. G.F. Nemet, Demand-pull, technology-push, and governmental-led incentives for non-incremental technical change, Research Policy, 38(5) (2009) 700-709.

35. C. Shepherd and P.K. Ahmed, From product innovation to solutions innovation: A new paradigm for competitive advantage, European Journal of Innovation Management, 3(2) (2000) 100-106.
36. E. Von Hippel, The Sources of Innovation, (Oxford University Press, New York, 1988).

37. D.H. Henard and D.M. Szymanski, Why some new products are more successful than others, Journal of Marketing Research, 38 (2001) 362-375.

38. K.Z. Zhou, C.K.B. Yim and D.K. Tse, The effects of strategic orientations on technology-and market-based breakthrough innovations, Journal of Marketing, 69 (2005) 42-60.

39. J.E. Ettlie and W.P. Bridges, Environmental uncertainty and organizational technology IEEE Transactions on Engineering Management, EM-29(1) (1982) 2-10.

40. A.L. Wilson, K. Ramamurthy and P.C. Nystrom, A multi-attribute measure for innovation adoption: The context of imaging technology, IEEE Transactions on Engineering Management, 46(3) (1999) 311-321.

41. M. Hitt, R. Hoskisson and R. Ireland, Mergers and acquisitions and managerial commitment to innovation in M-form firms, Strategic Management Journal, 11 (1990) 29-47.

42. R.G. Cooper, New products: The factors that drive success, International Marketing Review, 11(1) (1994) 60-76.

43. P. Humphreys, R. McAdam and J. Leckey, Longitudinal evaluation of innovation implementation in SMEs, European Journal of Innovation Management, 8(3) (2005) 283-304.

44. G.B. Voss and Z.G. Voss, Strategic orientation and firm performance in an artistic environment, Journal of Marketing, 64(1) (2000) 67-83.

45. G. Hamel and C.K. Prahalad, Competing for the Future, (Harvard Business School Press, Boston, 1994).

46. R. Srinivasan, G.L. Lilien and A. Rangaswamy, Technological opportunism and radical technology adoption: An application to e-business, Journal of Marketing, 66(3) (2002) 47-60.

47. E. Bueno and P. Ordonez, Innovation and learning in the knowledge-based economy: Challenges for the firm, International Journal of Technology Management, 27(6/7) (2004) 531-533.

48. D. Miller, Relating Porter's business strategies to environment and structure: Analysis and performance implications, Academy of Management Journal, 31(2) (1988) 280-308.

49. J.A. Keizer, L.D. Johannes and I.M. Halman, Explaining innovative efforts of SMEs: An exploratory survey among SMEs in the mechanical and electrical engineering sector in the Netherland, Technovation, 22(1) (2002) 1-13.

50. G.J. Avlonitis and H. Salavou Product innovation, product-market competition and persistent profitability in the US pharmaceutical industry, Strategic Management Journal, 20(7) (1999) 655-670.

51. H. Capon, J.U. Farley, D.R. Lehmann and J.M. Hulbert, Entrepreneurial orientation of SMEs, product innovativeness, and performance, Journal of Business Research, 60(5) (2007) 566-575. 
52. B. Scozzi, C. Garavelli and K. Crowston, Methods for modelling and supporting innovation processes in SMEs, European Journal of Innovation Management, 8(1) (2005) 120-137.

53. M.S. Freel, Where are the skills gaps in innovative small firms? International Journal of Entrepreneurial Behaviour \& Research, 5(3) (1999) 144-145.

54. C. Homburg and O. Jensen, The thought worlds of marketing and sales: Which differences make a difference? Journal of Marketing, 71 (2007) 124-142.

55. A. Aragon-Sanchez and G. Sanchez-Marin, Strategic orientation, management characteristics, and performance: A study of Spanish SMEs, Journal of Small Business Management, 43(3) (2005) 287-308.

56. R. Calantone, S. Cavusgil and Y. Zhao, Learning orientation, firm innovation capability, and firm performance, Industrial Marketing Management, 31 (2002) 515-524.

57. L. Klomp and G. van Leeuwen, Linking innovation and firm performance: A new approach, International Journal of the Economics of Business, 8(3) (2001) 343364.

58. J.C. Linder, Does innovation drive profitable growth? New metrics for a complete picture, Journal of Business Strategy, 27(5) (2006) 38-44.

59. U. Avci, M. Madanoglu and F. Okumus, Strategic orientation and performance of tourism firms: Evidence from a developing country, Tourism Management, 32 (2011) 147-157.

60. D.A. Dillman, Mail and Internet Survey: The Tailored Design Method, (John Wiley \& Sons Inc., Hoboken, 2007).

61. J.F. Hair, W.C. Black, B.J. Babin, R.E. Anderson and R.L. Tatham, Multivariate Data Analysis, (Pearson Education Inc., Upper Saddle River, 2006).

62. J.G. Covin and D.P. Slevin, New venture strategic posture, structure, and performance: An industry life cycle analysis, Journal of Business Venturing, 5(2) (1990) 123-135.

63. J. Armstrong and T. Overton, Estimating nonresponse bias in mail surveys, Journal of Marketing Research, 14 (1977) 396-402.

64. D.H. Doty and W.H. Glick, Common methods bias: Does common methods variance really bias results? Organizational Research Methods, 1(1) (1998) 374-406.

65. H. Wold, Partial least squares, in Encyclopaedia of Statistical Sciences, eds. S. Kotz and N.L. Johnson (Wiley, New York, 1985), pp. 581-591.

66. J. Henseler, C.M. Ringle and R.R. Sinkovics, The use of partial least squares path modeling in international marketing, New Challenges to International Marketing Advances in International Marketing, 20 (2009) 277-319.

67. V.E. Vinzi, W.W. Chin, W.W., J. Henseler and H. Wang, Handbook of Partial Least Squares: Concepts, Methods and Applications, (Springer-Verlag, Heidelberg, 2010).
68. M. Haenlein and A.M. Kaplan, A beginner's guide to partial least squares analysis, Understanding Statistics, 3(4) (2004) 283-297.

69. W.W. Chin, The partial least square approach for structural equation modeling, in Modern Methods for Business Research, ed. G.A. Marcoulides (Lawrence Erlbaum Associates, Mahwah, 1998), pp. 295-336.

70. D. Barclay, C. Higgins and R. Thompson, The partial least squares (PLS) approach to causal modeling: Personal computer adoption and use as an illustration, Technology Studies, 2(2) (1995) 285-309.

71. D. Gefen and D.W. Straub, A practical guide to factorial validity using PLS-Graph: Tutorial and annotated example, Communications of the AIS, 16(5) (2005) 91109.

72. M. Tenenhaus, V.E. Vinzi, Y-M. Chatelin and C. Lauro, PLS path modeling, Computational Statistics and Data Analysis, 48(1) (2005) 159-205.

73. M. Wetzels, G. Odekerken-Schröder and C. van Oppen, Using PLS path modeling for assessing hierarchal construct models: Guidelines and empirical illustration, MIS Quarterly, 33(1) (2009) 177-195.

74. J. Cohen, Statistical Power Analysis for the Behavioral Sciences (Lawrence Erlbaum, Hillsdale, 1988).

75. B.S. Cumming, Innovation overview and future challenges, European Journal of Innovation Management, 1(1) (1998) 21-29.

76. M.U. Maldonado, N. Dias and G. Varvakis, Managing innovation in small high technology firms: A case study in Brazil, Journal of Technology Management and Innovation, 4(2) (2009) 130-142. 